NBER WORKING PAPER SERIES

\title{
THE EFFECT OF FDA ADVISORIES ON BRANDED PHARMACEUTICAL FIRMS' VALUATIONS AND PROMOTION EFFORTS
}

\author{
Rena M. Conti \\ Haiden A. Huskamp \\ Ernst R. Berndt \\ Working Paper 17528 \\ http://www.nber.org/papers/w17528
}

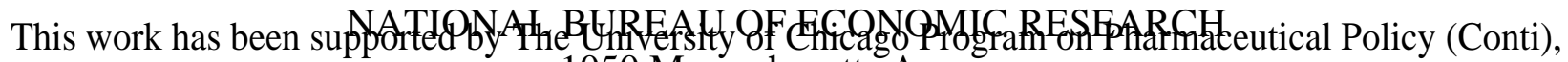

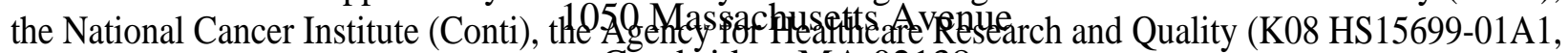

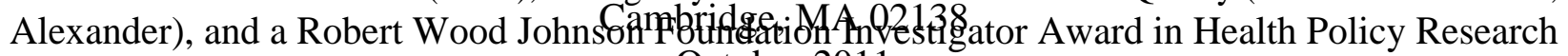
(Huskamp). The funding sources had no roletipesturdld design or conduct; collection, management, analysis, or interpretation of the data; or preparation, review, or final manuscript approval. The authors gratefully acknowledge E. Ray Dorsey and G. Caleb Alexander for their review of the clinical content of the analysis and comments on previous drafts. Comments by participants in the Health Economics Workshop and the Department of Health Studies Research in Progress Workshop at The University of Chicago and the Food and Drug Administration's Office of Surveillance and Epidemiology Safety Seminar (May 19, 2011) are gratefully acknowledged. Wharton Research Data Services (WRDS) was used to retrieve stock market data. This service and the data available thereon constitute valuable intellectual property and trade secrets of WRDS and/or its third-party suppliers. The statements, findings, conclusions, views, and opinions contained and expressed herein are based in part on data obtained under license from the IMS Health Incorporated information services: Integrated Promotional Services ${ }^{\mathrm{TM}}$ (2004-2006) and the National Disease and Therapeutic Index TM (NDTI). All Rights Reserved. The statements, findings, conclusions, views, and opinions contained and expressed herein are those of the authors and are not necessarily those of the research sponsors, the National Bureau of Economic Research, the institutions with whom the authors are affiliated, of IMS Health Incorporated or any of its affiliated or subsidiary entities. Expert research assistance was provided by Anna Zelivianskaia, Ravi Gupta and Arielle Bernstein.

NBER working papers are circulated for discussion and comment purposes. They have not been peerreviewed or been subject to the review by the NBER Board of Directors that accompanies official NBER publications.

(C) 2011 by Rena M. Conti, Haiden A. Huskamp, and Ernst R. Berndt. All rights reserved. Short sections of text, not to exceed two paragraphs, may be quoted without explicit permission provided that full credit, including $\odot$ notice, is given to the source. 
The Effect of FDA Advisories on Branded Pharmaceutical Firms' Valuations and Promotion Efforts

Rena M. Conti, Haiden A. Huskamp, and Ernst R. Berndt

NBER Working Paper No. 17528

October 2011

JEL No. D22,D43,I11,I18,K23,L1,L11

\begin{abstract}
The US Food and Drug Administration (FDA) expends considerable efforts in regulating medications approved for use. Yet the impact of medication labeling changes on brand pharmaceutical products, and whether and what firms do to respond to increased information regarding the safety and efficacy of a drug, have not be characterized. We propose a behavioral framework for examining the effects of FDA advisories on branded pharmaceutical firms and their products. We empirically assess the impact of recent FDA advisories on the stock market valuations of a sample of branded pharmaceutical manufacturing firms using event study methods. We examine whether and how branded pharmaceutical manufacturers respond to an advisory by assessing changes in promotion compared to non-affected firms. We find firms targeted by an advisory have average stock price declines of $3 \%$ in three days and $11 \%$ in five days following the advisory release, and in turn appear to decrease total physician-directed promotion spending, journals ads and detailing visits significantly six months following the advisory release; the provision of free samples is unaffected. We find no changes among therapeutic substitutes unaffected by the advisory. Results of sensitivity analyses suggest firms with market dominant positions experience similar decreases in stock market valuations and physician-directed promotion compared to pooled results. The results are also robust to alternative definitions of the timing of advisory release dates and the severity of advisories' wording. Theory and empirical results suggest the public release of FDA advisories negatively impacts firm's short-term market valuations. The results suggest an additional rationale for previously documented declines in prescribing after FDA advisory releases - significant declines in physician-directed promotion following FDA advisory releases; the combined (and likely correlated) effects of the release of the advisory and declines in physician-directed promotion on prescribing behavior are likely larger than the sum of the independent effects.
\end{abstract}

Rena M. Conti

University of Chiccago

Department of Pediatrics

Section of Heamtology/Oncology

5812 S. Ellis Street

Chicago, IL 60637

rconti@uchicago.edu

Haiden A. Huskamp

Harvard Medical School

Dept. of Health Care Policy

180 Longwood Avenue

Boston, MA 02115

huskamp@hcp.med.harvard.edu
Ernst R. Berndt

MIT Sloan School of Management

100 Main Street, E62-518

Cambridge, MA 02142

and NBER

eberndt@mit.edu 


\section{INTRODUCTION}

The United States Food and Drug Administration (FDA) requests labeling changes and issues advisories to communicate important new prescription drug safety and efficacy information through its Medwatch system to American health care providers and the public. ${ }^{1,2}$ The Sentinel Initiative, a drug safety monitoring system enacted as part of the 2007 FDA Amendments Act, increases the role of the FDA's Office of Surveillance and Epidemiology (OSE) in evaluating new safety information available after the market launch of a prescription drug in the United States (US). Several analyses have estimated the magnitude and timing of changes in physician prescribing of drugs following FDA-requested labeling changes and public health advisories (PHAs) including but not limited to black box warnings, ${ }^{3}$ while others have examined how PHAs impact the frequency of clinical monitoring or patient morbidity and mortality. 4

Although these studies offer important insights, they neglect analyses of the impacts of PHAs on pharmaceutical firms. The lay press $^{5}$ and economic theory ${ }^{6}$ suggest firm market

\footnotetext{
${ }^{1}$ See US Food and Drug Administration, 2007. Guidance drug safety information - FDA's communication to the public. January 2007. Available at: http://www.FDA.gov/cder/guidance/7477fnl.htm\#_Toc159824037. (Accessed May 27, 2009).

2 See Hamburg MA, Sharfstein JM. The FDA as a public health agency. New England Journal of Medicine. 2009;360:2493-2495 and Law Strengthens FDA. Available at: http://www.FDA.gov/oc/initiatives/advance/FDAaa.html (Accessed January 21, 2009). ${ }^{3}$ See Jacoby JL, Fulton J, Cesta M, Heller M. After the black box warning: dramatic changes in ED use of droperidol. American Journal of Emergency Medicine. 2005;23:196; Morgan OW, Griffiths C, Majeed A. Interrupted time-series analysis of regulations to reduce paracetamol (acetaminophen) poisoning. PLoS Med. 2007;4:e105; Smalley W, Shatlin D, Wysowski DK, et al. Contraindicated use of Cisapride: impact of Food and Drug Administration Regulatory Action. Journal of the American Medicine Association. 2000;284:3036-3039.

4 See Gibbons RD, Brown H, Hur K, et al. Early evidence on the effects of regulators' suicidality warnings on SSRI prescriptions and suicide in children and adolescents. American Journal of Psychiatry. 2007;164:1356-1363; Nemeroff CB, Kalali A, Keller MB, Charney DS, Lenderts SE, Cascade EF, Stephenson H, Schatzberg AF. Impact of publicity concerning pediatric suicidality data on physician practice patterns in the US. Archives of General Psychiatry. 2007;64:466-472; Katz LY, Kozyrskyj AL, Prior HJ, et al. Effect of regulatory warnings on antidepressant prescription rates, use of health services and outcomes among children, adolescents and young adults. CMAJ. 2008;178:1005-1011. ${ }^{5}$ See Gardner J. When a Patent-protected drug gets hit by bad news. US News World Rep. November 1992;8:71; Damage control. AdWeek [Western ed]. November 25, 1996;46:3;
} 
valuations may be affected by the public release of information altering the perceived quality of a prescription drug. ${ }^{6}$ Firms marketing patent-protected prescription drugs may respond strategically to such developments via price-setting and/or promotion strategies. Quantifying the direction, magnitude and correlation between market valuation changes and changes in prescription drug price-setting and promotion after the release of a PHA are important for the FDA's ability to interpret patient and provider responses to previously released PHAs, and in anticipating reactions to future PHAs.

In this paper we propose a behavioral framework and derive specific hypotheses for examining the effects of PHAs on the stock market valuations of pharmaceutical firms and whether and how firms may respond to PHAs. We then investigate these hypotheses using empirical data. This is the first paper we have identified in the literature that theoretically and empirically investigates the impact of PHAs on firms' market valuations and strategic decision-making.

\section{CONCEPTUAL FOUNDATIONS AND TESTABLE HYPOTHESES}

A review of previous theoretical and empirical work establishes a behavioral framework for the empirical analyses (Chart). Following Scherer (1993), we assume manufacturers of pharmaceutical drugs may possess market power enabling them to set prices exceeding marginal costs. ${ }^{7}$ Market power is primarily conferred by patent protection, which prohibits another firm from selling the same drug between the FDA's approval of the drug for marketing in the US and its expiration. Previous research suggests marketing efforts are a

Zate M. Two words you won't see: apologize, regret. Ventura County Star. August 26, 2000:D01.

${ }^{6}$ See Berndt, ER, Kyle MK, Ling DC. The Long Shadow of Patent Expiration: Generic Entry and Rx-to-OTC Switches, Scanner Data and Price Indexes. (Robert C. Feenstra and Matthew D. Shapiro, eds, 2003); Huskamp HG, Donohue JM, Koss C, Berndt ER, Frank RG. Generic Entry, Reformulations and Promotion of SSRIs in the U.S. Pharmacoeconomics. 2008;26:603-616;

Suh DC, Manning WG, Schondelmeyer S, Hadsall RS. Effect of Multiple-Source Entry on Price Competition After Patent Expiration in the Pharmaceutical Industry. Health Services Research. 2000;35:529-547.

7 See Scherer F.M. Pricing, Profits, and Technological Progress in the Pharmaceutical Industry. The Journal of Economic Perspectives. Vol. 7, No. 3 (Summer, 1993), pp. 97-115. The marginal production costs for small drug medications are typically assumed to be low. 
key determinant of demand for prescription drugs. ${ }^{8}$ Close to $\$ 30$ billion was devoted to prescription drug promotion in 2008, suggesting the importance of this spending among firms to build and maintain market share. ${ }^{9,10}$

The efficient markets tradition in financial economics suggests capital markets instantaneously incorporate all relevant information into the stock price of a publicly traded firm. ${ }^{11}$ This implies share prices should change quickly when the market receives value relevant information. Panattoni (2011) uses this framework to investigate the impact of Paragraph IV patent infringement decisions on a representative sample of pharmaceutical firms. Such decisions determine whether another firm can enter its nonbranded product into the market before patent expiration. ${ }^{12}$ Findings suggest Paragraph IV decisions have considerable consequences for firms: two-day stock price valuations for firms marketing the patent-protected drug decrease 5.2 percent and trading volumes increase when courts awarded permission to enter the market to generic manufacturing firms. Consequently, we hypothesize:

(H1) Firms whose drugs are targeted by a PHA will experience short-term decreases in stock valuation and increases in trading volume (Chart).

The derived demand for medical care tradition in health economics suggests physicians (as agents for their patients) choose treatments based on their perceived marginal benefits over

${ }^{8}$ Avorn J, Chen M, Hartley R. Scientific versus commercial sources of influence on the prescribing behavior of physicians. American Journal of Medicine. 1982;73:4-8; Donohue JM, Cevasco M, Rosenthal MB. A decade of direct-to-consumer advertising of prescription drugs. New England Journal of Medicine. 2007;357:673-681.

9 IMS Health. Top-line industry data: total US promotion spend by type. 2008 [online]. Available from: http://www.imshealth.com/deployedfiles/imshealth/Global/Content/StaticFile/Top_Line_ Data/U.S._Promo_Spend_Data_2008.pdf (Accessed 11.8.2009).

${ }^{10} \mathrm{~A}$ firm maximizing its profits will promote up to the point where the incremental revenues just equal the sum of the incremental marketing and production costs.

11 See Brown S, Warner J. Using daily stock returns: The case of event studies. Journal of Financial Economics 1985;14:3-31; Campbell J, A Lo, AC MacKinlay. The Econometrics of Financial Markets. Princeton University Press, 1997.

12 See Panattoni LE, The effect of Paragraph IV decisions and generic entry before patent expiration on brand pharmaceutical firms, Journal of Health Economics. 2011;30(1):126145. 
"costs". ${ }^{13}$ Consequently, a physician's treatment decision-making should be influenced by a firm's choice of prices and promotion of medical treatments, such as patent protected drugs. ${ }^{14}$

The conjectural variations literature provides a model for a biopharmaceutical firm's choice of prices and promotion for a patent-protected drug. A profit-maximizing oligopolistic firm facing a downward sloping linear demand curve should set its optimal price-cost margin ([p $-\mathrm{MC}] / \mathrm{p}$, where $\mathrm{p}$ is price and $\mathrm{MC}$ is marginal production cost) equal to the inverse of the absolute value of the demand elasticity with respect to price. Its optimal promotional intensity (promotion expenditures/sales ratio, A/R) will be set equal to the product of the price-cost margin times the sum of the elasticity of demand with respect to its own promotion, , $\eta_{A}$, plus the elasticity of its rival's advertising in response to the firm's own promotion, $\eta_{A r, A}$, times the elasticity of the firm's own demand with respect to the its rival firm's promotion, $\eta_{A r}-$ see (1). ${ }^{15}$

$$
\frac{A}{R}=\frac{p-M C}{p}\left(\eta_{A}+\eta_{A r, A} * \eta_{A r}\right) .
$$

Since the product of the positive term $\eta_{A r, A}$ (the rival firm's promotion response to own firm's promotion change) and the negative term $\eta_{A r}$ (the effect of the rival's increased firm promotion on own firm demand) is negative, own firm's optimal choice of the A/R ratio is potentially negatively offset by the rival firm's promotion and price setting. The model implies the marginal profitability from promotion increases as the price elasticity of demand for the good decreases in absolute value, ceteris paribus. Furthermore, firms should alter the pricing and/or promotion intensity of a drug based on anticipated changes in its own price elasticity of demand. PHAs will likely result in an increase in the absolute value of demand elasticity for the drug with respect to price, and consequently a reduction in the firm's gross margin on that product, ceteris paribus.

Based on this model, we hypothesize (Chart):

${ }^{13}$ See Grossman M. Chapter 7: The human capital model. In Culyer AJ and Newhouse JP (editors) Handbook of Health Economics, first edition. North Holland: Elsevier, 2000. The costs include impacts resulting from side effect profiles. They may also include the marginal price of the product for a course of therapy.

14 See Dorfman R, Steiner PO. Optimal Advertising and Optimal Quality. The American Economic Review. 1954; 44(5):826-836.

${ }^{15}$ See Schmalansee R. The economics of advertising. Amsterdam, North Holland Inc, 1972. 
(H2) Following the release of a PHA targeting their patent-protected drug, biopharmaceutical firms will anticipate changes in revenue and consequently alter promotion intensities.

(H3) Based on Palda $(1969,1973)$ and Huskamp et al. (2008), firm changes in promotion expenditure intensity will extend to setting optimal intensities among different promotion channels, where under an assumption of constant unit promotion costs the optimal ratio of spending for any two promotion channels equals the ratio of their promotion elasticities. ${ }^{16}$ (H4) Firms will also alter pricing intensities after the release of a targeted PHA.

Changes in strategy will likely occur weeks to months after the PHA's release since they involve communications with the FDA, within firm decision-making and between firm contracting (Chart).

The effects of PHAs may act differentially based on the market power commanded by the targeted drug. The Dorfman-Steiner model suggests market power is conferred through the term relating the revenue generation of one product to the firm's total revenue. Previous empirical work suggests the order of a drug's entry into a therapeutic class and subsequent market share in terms of class utilization are additional indicators of market power (and strongly correlated with pricing and promotion). ${ }^{17,18}$ Consequently, we hypothesize, (H5) Following a PHA, changes in a firm's market valuation, drug pricing and/or promotion may be correlated with its preceding market power (Chart*). ${ }^{19}$

\footnotetext{
16 See Huskamp HG et al 2008; Palda KS. Does Advertising Influence Votes? An Analysis of the 1966 and 1970 Quebec Elections. 1973; Canadian Journal of Political Science / Revue canadienne de science politique 6(4):638-655 ; Palda KS. Economic analysis for marketing decisions. Englewood Cliffs, N.J., Prentice-Hall, 1969; Jean-Jacques Lambin. Optimal Allocation of Competitive Marketing Efforts: An Empirical Study. The Journal of Business. 1970;43(4):468-484. Narayanan S, Desiraju R, Chintagunta PK. Return on Investment Implications for Pharmaceutical Promotional Expenditures: The Role of Marketing-Mix Interactions. The Journal of Marketing. 2004;68(4):90-105.

17 See Rosenthal MB, Berndt ER, Donohue JM, Epstein AM, Frank RG 2003; Urban GL, Carter T, Gaskin S, Mucha Z. Market Share Rewards to Pioneering Brands: An Empirical Analysis and Strategic Implications. Management Science. 1996;32(6), June, 645-659; Scott Morton F. Entry Decisions in the Generic Pharmaceutical Industry Entry Decisions in the Generic Pharmaceutical Industry. The RAND Journal of Economics. 1999;30(3):421-440.

18 This is also consistent with FDA practice: the OSE considers the number and benefit/risk tradeoff of potential therapeutic substitutes when assessing the evidence in support of issuing a Medwatch safety advisory for a specific drug and its content. See Hamburg MA, Sharfstein JM 2009.

${ }^{19}$ In practice, the Federal Food, Drug and Cosmetic Act requires drug labels and promotional materials contain all risk information in "brief summary" relating to side
} 
We refine these hypotheses for empirical consideration based on economic theory and practical constraints. First, economists have debated whether pharmaceutical marketing serves a largely informational or persuasive role. ${ }^{20}$ If promotion is strictly informational, it acts to increase patient and physician awareness of treatment options. ${ }^{21}$ If promotion is strictly persuasive, it acts to create "artificial" perceptions of benefit/costs among potential therapeutic substitutes and may cause physicians to prescribe a particular drug based on habit.22,23 The evidence in support of pharmaceutical promotion being informational or persuasive is mixed, suggesting both functions are operative. Generally, studies support the hypothesis that the informational role dominates in the beginning of a drug's life-cycle with the persuasive role taking over as uncertainty regarding quality is resolved. ${ }^{24}$ Consequently, we refine H2' (and by extension H3') to suggest:

effects, contraindications and effectiveness. Promotional materials cannot be false or misleading or omit material facts and must present a "fair balance" between effectiveness and risk information. The FDA's Division of Drug Marketing, Advertising, and Communications (DDMAC) is responsible for the practical enforcement of these responsibilities. In the case of revisions to the known benefit/risk ratio of a patentprotected drug, the Act requires firms to initiate revisions to the product label and related promotional materials. DDMAC prioritizes its review of promotion materials, including revisions of brief summaries for marketed drugs, using a risk-based approach. The review process has variable timing and may include direct interactions between pharmaceutical firm representatives and DDMAC staff, largely unobservable by the public. Consequently, the release of a PHA will likely change the content of promotion efforts due to branded firms' compliance with FDA regulatory enforcement. These changes could be made without altering the overall level of promotion spending on a drug. However, changes in the content of drug promotion is beyond the scope of this analysis and consequently left for future work.

${ }^{20}$ See Leffler KB. Persuasion or Information? The Economics of Prescription Drug Advertising. Journal of Law and Economics. 1981;24(1): 45-74; Hurwitz MA, Caves RE. Persuasion or Information? Promotion and the Shares of Patent-protectedPatent-protected and Generic Pharmaceuticals. Journal of Law and Economics. 1988;(31)2: 299-320; Lakdawalla D, Philipson T, Wang YR. Intellectual Property and Marketing. NBER Working Paper No. 12577 2006; Berndt ER. To inform or persuade? Direct-to-consumer advertising of prescription drugs. New Engl Jnl Medicine 352:4:325-8, January 27, 2005.

${ }^{21}$ Consistent with the literature, such promotion does not affect the shape of a drug's demand elasticity with respect to price but may shift its intercept, ceteris paribus.

22 See Lakdawalla D, Philipson T, Wang YR 2006.

${ }^{23}$ Consistent with the literature, persuasive promotion reduces a drug's demand elasticity with respect to price, ceteris paribus.

24 See Hurwitz MA and Caves RE 1988; Leffler KB 1981; Gonul F, Carter F, Petrova E, Srinivasan K. Promotion of Prescription Drugs and Its Impact on Physicians' Choice Behavior. J. Marketing. 2001; 65(3):79-90; Rizzo JA. Advertising and Competition in the Ethical Pharmaceutical Industry: The Case of Antihypertensive Drugs. Journal of Economics 
(H2'/H3') If branded promotion is generally informational in nature, the PHA should result in either (1) no change in promotion expenditure and promotion channel intensity; or (2) an increase in promotion intensity to inform existing consumers of the drug's updated benefit/cost tradeoff. If patent-protected promotion is generally persuasive, then the PHA should result in a decrease in promotion intensity since this information would make promotion less effective in softening the drug's demand response to price, ceteris paribus. Testing $\mathrm{H} 4$ in empirical data requires researchers to observe pricing changes in the market. While empirical evidence suggests pharmaceutical pricing may change due to developments in market competition ${ }^{25}$, the external validity of this evidence is limited since these studies rely on observed changes in list prices. List prices for patent-protected therapies likely mismeasure transaction prices with unknown bias due to the presence and proprietary nature of discounts, rebates and charge-backs. ${ }^{26}$ The direction and magnitude of the relative pricing bias between drugs is unknown. Consequently, we do not pursue an empirical test of $\mathrm{H} 4$.

\section{RESEARCH DESIGN}

\section{Sample Selection Methods and Data}

We empirically evaluate $\mathrm{H} 1, \mathrm{H} 2$ ' and H3' in a panel of patent-protected prescription drugs for which the FDA's OSE released a PHA requiring labeling changes between 2004 and 2009 , and compare impacts on them to similar medications untargeted by a simultaneous PHA. Data were obtained on the number and nature of all PHAs released between January

and Law 1999;42: 89-116; Narayanan S, Manchanda P, Chintagunta P. Temporal Differences in the Role of Marketing Communication in New Product Categories. Journal of Marketing Research. 2005;42:278-90; Rosenthal MB, Berndt ER, Donohue JM, Epstein AM,Frank RG. Demand Effects of Recent Changes in Prescription Drug Promotion. Frontiers in Health Policy Res. 2003; 1-26; Azoulay P. Do Pharmaceutical Sales Respond to Scientific Evidence? Journal of Economics and Management Strategy. 2002;11(4): 551-594; Berndt ER, Bui L, Reiley DR, Urban GL. Information, marketing, and pricing in the U.S. antiulcer drug market. American Economic Review. 1995;85(2):100-5.

25 See Huskamp HG et al 2008; Frank RG, Salkever DS. Generic entry and the pricing of pharmaceuticals. Journal of Economics and Management Strategy. 1997;6:75-90; Meltzer DM, Basu A, Conti R. The economics of comparative effectiveness studies: societal and private perspectives and their implications for prioritizing public investments in comparative effectiveness research. Pharmacoeconomics. 2010;28(10):843-53. 26 See Academy of Managed Care Pharmacy Guide to Pharmaceutical Payment Methods. Task force on drug payment methodologies. October 2007. 
2000 and December 2010 listed on the Medwatch website. ${ }^{27}$ PHAs targeting all members of a therapeutic class were excluded; promotion within class is likely to be complicated by strategy beyond the scope of current efforts and available data. PHAs targeting drugs only available in generic formulation were excluded since these products are rarely promoted 28 ; PHAs targeting over-the-counter medications, devices and specialty drugs were excluded since they are typically not promoted using traditional methods. The final sample consists of nine drugs (Table 1).

The FDA Orange Book was used to abstract the name of the originating firm, approval dates, patent expiry dates, FDA approvals for secondary indications, drug reformulations and the presence of generic formulations for all sample drugs. ${ }^{29}$ A review of DDMAC regulatory enforcements did not find overlap between sample drugs and other regulatory actions involving them in the twelve months preceding and following each advisory.

To measure the value effect of PHAs on pharmaceutical firms, data were obtained on average daily stock price valuations and trading volumes for the firms marketing the sample drugs as listed on either the New York Stock Exchange ${ }^{\mathrm{TM}}$ (NYSE) or the NASDAQ ${ }^{\mathrm{TM}}$ from the CRSP Daily Stock Market Composite Index ${ }^{\mathrm{TM}} .{ }^{30}$

Data regarding monthly physician-directed promotion for each sample drug was obtained from IMS Health's Integrated Promotional Services ${ }^{\mathrm{TM}}$ (IPS) database, 2003- 2010. This data window included a 12-month period prior to and following each PHA, providing enough observations to generate statistically meaningful estimates while reducing the risk of incorporating longer-term secular trends and market dynamics that might confound the

\footnotetext{
${ }^{27}$ See The US Food and Drug Administration. Public Health Advisories (Drugs). Available at http://www.FDA.gov/Drugs/DrugSafety/PublicHealthAdvisories/default.htm.

28 We did not exclude from the sample drugs for which authorized patent-protected generics were available at the time of the advisory, and drugs for which the parent compound was available in generic form, but where drug line extensions (e.g. extended release versions of the parent compound) remained patent-protected at the time of the advisory.

${ }^{29}$ Electronic orange book - approved drug products with therapeutic equivalence evaluations. Available at: http://www.FDA.gov/cder/ob/default.htm (Accessed 11.1.2009).

${ }^{30}$ Firms' year-end reports to shareholders available online were also reviewed to ascertain whether there were any merger, acquisition, or in-licensing arrangements during the study period which would directly alter the incentives for brand level promotion at the firm level.
} 
associations of interest. Four promotion domains were examined: total promotion spending, ${ }^{31}$ number of visits of pharmaceutical sales representatives to physicians in officebased practices ("detailing"), number of free samples provided to physicians, and counts of journal advertisements. These activities accounted for approximately $98 \%$ of physiciandirected promotion. Measure derivation and definition have been described previously. ${ }^{32}$

Firms' quarterly and year-end reports to shareholders (10Q and 10K) available online were reviewed to ascertain data on firm revenue overall and by drug preceding the PHA release. We were able to obtain $10 \mathrm{~K}$ reports for eight out of the nine manufacturing firms in the sample. Worldwide drug-specific revenue was available in all $10 \mathrm{~K}$ reports but quarterly revenue was available for three sample drugs. Consequently, we were unable to match the timing of the release of each PHA to drug specific revenues in the preceding quarter for the full sample. Therefore, the main measures of total promotion expenditures and promotion by channel is in levels, unadjusted for sales. ${ }^{33}$ Total promotion spending was transformed into 2009 \$US using the Bureau of Labor Statistics CPI-all urban items calculator.

Therapeutic substitutes were matched to sample drugs via the American Therapeutics Committee (ATC) standard designations (Table 1, last column). When the drug was the only member of a class, two practicing physicians were conferred with to identify clinically valid alternative class designations. There were eighty-six drugs matching sample drugs using this classification. Thirty-eight therapeutic substitute drugs were available in patentprotected form during this period. Promotion of these therapeutic substitutes was also measured using IPS data.

To empirically test H5, drugs with "market power" were defined as those that were first-inclass, and/or were responsible for revenue comprising more than 10 percent of the parent firm's total revenue for the year preceding the PHA, and/or had usage comprising more

31 Total expenditures include spending on detailing visits, journal advertisements and the retail value of free samples.

32 See Zell ER, McCaig LF, Kupronis BA, Besser RE, Schuchat A. A comparison of the National Disease and Therapeutic Index ${ }^{\mathrm{TM}}$ and the National Ambulatory Medical Care Survey ${ }^{\mathrm{TM}}$ to evaluate antibiotic usage. Available at: http://amstat.org/sections/srms /Proceedings (Accessed July 11, 2008).

33 Similar to Gonul F, Carter F, Petrova E, Srinivasan K 2001, Rizzo JA 1999, Narayanan S, Manchanda P, Chintagunta P 2005 and Lakdawalla D, Philipson T, Wang YT 2006. 
than 20 percent of class usage in the month preceding the PHA. ${ }^{34}$ The first two measures were based on ATC classification and $10 \mathrm{~K}$ reports. To characterize drug usage prior to each PHA, the National Disease and Therapeutic Index ${ }^{\mathrm{TM}}$ (NDTI) was used to derive estimates of market usage share (measured in prescription units in the month preceding the PHA) for each drug relative to usage of all therapeutic class substitutes (Table 1, second to last column). The NDTI has been used in previous efforts to examine office-based prescribing behavior and is similar in coverage and scope to the National Ambulatory Care Medical Survey, a nationally representative survey of office-based physicians conducted by the National Center for Health Statistics. ${ }^{35}$

Gabitril, Adderall and Chantix accounted for more than 20 percent of all usage in their respective therapeutic class at the time of the PHA release; Strattera and Chantix were first entrants into their therapeutic class; and Duragesic, Crestor and Adderall were responsible for 10 percent or more of parent firm revenue in the year preceding the PHA. Hence we consider them "market dominant" drugs; the remaining three agents (Paxil, Elidel, Ketek) are considered non-dominant market drugs. The branded therapeutic substitutes of market dominant drugs numbered twenty-seven.

\section{Analytical Methods}

The Medwatch reported date of PHA release is the main timing instrument.

Standard event study methods were employed to test H1 in the full sample: an OLS regression correlating the advisory release to three- and five-day changes in the direction

34 We also estimate changes in the counts of specific promotions in this subsample (results not reported).

35 The NDTI collects data two days per quarter from a sample of 4,800 office-based physicians in the US and applies sample weights to derive nationally representative estimates. See Alexander GC, Sehgal NL, Moloney RM, Stafford RS. National trends in treatment for Type 2 diabetes mellitus, 1994-2007. Archives of Internal Medicine. 2008;168:2088-2094;

Dorsey ER, Rabbani A, Gallagher SA, Conti R, Alexander GC. The impact of black box warnings on the use of atypical antipsychotic medicines. Archives of Internal Medicine 2010;170:96-103; Stafford RS, Radley DC. The underutilization of cardiac medications of proven benefit, 1990 to 2002. Journal of the American College of Cardiology, 2003;41:5661; Zell ER, McCaig LF, Kupronis BA, Besser RE, Schuchat A. A comparison of the National Disease and Therapeutic Index ${ }^{\mathrm{TM}}$ and the National Ambulatory Medical Care Survey ${ }^{\mathrm{TM}}$ to evaluate antibiotic usage. Available at: http://amstat.org/sections/srms /Proceedings (Accessed July 11, 2008). 
and magnitude of average firm stock market valuation and trading volume in the NYSE/NASDAQ Composite Index. ${ }^{36}$ These changes were compared to estimated changes in the price and volume of the NYSE/NASDAQ Composite Index over the corresponding period, and to those experienced by the same firms for which a drug was the subject of a district court Paragraph IV decision 2003-2009, but not the subject of a PHA. Identification and timing of this comparison sample was taken from Panettoni (2011) (Appendix). Theoretically, Paragraph IV ruling adverse to a firms' patent-protected drug should result in smaller stock market valuation decreases than PHAs, in part because Paragraph IV filings affect only six months of a drug's marketing exclusivity, whereas PHAs affect the drug's entire remaining patent term (Chart).

To test H2' and H3', monthly promotion expenditures and counts of detailing visits, journal advertisements and free samples over all drugs were examined. Spending estimates and counts preceding and following each PHA were tested for statistically significant differences using the Student's t-test. The Durbin-Watson test was used to examine the data for potential first order serial correlation. To account for observed serial correlation ${ }^{37}$, generalized estimating equations (GEE) were used to estimate the direction, magnitude and significance of promotion following the PHA compared to promotion preceding the PHA. ${ }^{38} \mathrm{~A}$ log-link function that assumed error distributions based on the nature of the outcome variables (e.g. negative binomial for count data and gamma distribution for possibly skewed expenditure measures) was used, and all coefficients were transformed into interpretable units by exponentiation. Drug-level random effects were included in all models and interacted with monthly dummy variables to account for potential independent alterations in the competitive landscape.

To test H5, we re-estimated the models restricted to the market dominant sample drugs and their therapeutic substitutes.

Analyses were performed using Stata version 10.1 (College Station, TX). Estimated changes were considered statistically significant at the tor $\mathrm{z}$ statistic equal to 2.00 or greater in

\footnotetext{
36 See Campbell, Lo, MacKinlay 1997.

${ }^{37}$ See Huskamp et al 2008.

38 See Hardin JW, Hilbe JM. Generalized estimating equations. Boca Raton, FL: Chapman \& Hall, 2003.
} 
absolute value.

\section{Sensitivity Analyses}

The main weakness of the analytic method is an assumption that each PHA is a public and exogeneous "shock" to the market. However, the exact time of day when each PHA was released is unknown. Some PHAs could have been made after the market closed on the release day. In these cases, a change in the stock market performance would be delayed. Additionally, leakage of the PHA could have occurred prior to the day of the announcement leading to anticipatory valuation changes. Other announcements regarding firm activities independent, but coincident with the PHA could have independently affected firm valuations.

Consequently, the timing and content of media reports mentioning the drug, the PHA and/or the firm were examined. Academic LexisNexis was searched using these terms in major world publications for the period beginning one-month prior to and ending onemonth following each PHA release ${ }^{39}$ For PHAs announced in the press previous to the official FDA release date, the models were re-estimated with this release date. For the firms with coincident announcements affecting firm value, the models were re-estimated at the drug level.

We also examined whether there was evidence supporting the hypothesis that PHAs containing more severe wording regarding potential side effects of the drug had more appreciable effects on firm stock market valuation and/or promotion than less severe PHAs. Sample PHAs were segregated into those that did and did not contain a reference to "severe" side effects or "death" (bolded in Table 1, $4^{\text {th }}$ column). The models were reestimated on this stratified sample.

Finally, PHA releases are the product of ongoing FDA-firm level communications and negotiations. Consequently, the release of each PHA may be an "exogenous" shock to the market but may not be to the drug's firm. ${ }^{40}$ Anticipating the FDA's announcement, it is

\footnotetext{
${ }^{39}$ See http://www.lexisnexis.com/hottopics/lnacademic/.

${ }^{40}$ Sources within the FDA indicate that the date of the advisory release may be unanticipated by the firm, but the presence of the safety review by the OSE staff and safety review board will be known by the firm.
} 
possible firms may undertake strategies biasing the estimated results. For example, the results of the valuation models could be biased downward if the presence of FDA investigation of safety concerns for a specific drug and ongoing discussions between firms and the FDA regarding labeling changes are pre-emptively reported to stock-holders; the promotion results could be biased in either direction if firm marketing departments alter promotion intensities in anticipation of the negative effect of the PHA on sales. We examine raw trends 12 months preceding each PHA by drug to detect possible anticipatory preemptive behavior by firms in each outcome measure

\section{RESULTS}

Table 2 reports (top panel) logged OLS estimates of changes in average daily stock market valuations and trading volumes for firms 3- and 5-days following PHAs. Firms whose drugs are the targets of a PHA appear to have average stock price declines of 3\% with 3- days and $11 \%$ within 5- days following the release. These firms also appear to have non-statistically significant average trading volume increases of $17 \%$ within 3 - days and $16 \%$ within 5 - days following the release. There are no coincident changes in prices and/or trading volume in the NYSE/NASDAQ Composite Index (middle panel). Matched firms manufacturing a drug that was the subject of a Paragraph IV district court decision experienced a non-statistically significant average 1\% decline in stock valuation 3- days after the court found in favor of the generic manufacturer and a statistically significant average $2 \%$ increases in stock valuation 3- days after the court found in favor of the branded firm (bottom panel). Estimated 5- day stock price changes are similar in magnitude to those estimated for 3days. For branded firms experiencing favorable Paragraph IV District Court decisions, volume increases were $23 \%$ after 3 - days (trending toward significance) and 34\% after 5days (significant); branded firms experiencing decisions favoring generic firms did not experience appreciable volume changes.

Table 3 reports (top panel) pooled GEE estimates of changes in promotion 3- months, 6months and 12- months after PHA releases among targeted drugs. 3- months after a PHA we find statistically significant $83 \%$ decreases in journal ads and 29\% declines in detailing visits to physicians. Estimated reductions in total promotion spending and the number of free samples are not statistically significant. 6- months after PHAs' release we estimate statistically significant $46 \%$ decreases in total promotion spending, $45 \%$ declines in 
detailing visits to physicians and $84 \%$ declines in journal ads. The number of free samples also declined, but the reduction was not statistically significant. 12- months after PHAs' release non-statistically significant decreases in promotion expenditures and promotion by channel are observed. Table 3 (bottom panel) reports GEE estimates of changes in promotion 3- months, 6- months and 12- months after PHAs release among the 38 branded therapeutic substitutes of the PHA targeted drug. We did not find statistically significant changes in promotional expenditures overall or by channel in this sample coincident with targeted PHAs.

Table 4 reports (top panel) pooled stock market valuation models restricted to the seven market-dominant drugs in the sample targeted by a PHA. Results are similar in magnitude and direction to those reported in the results for the pooled sample (Table 2), albeit smaller in absolute magnitude. Hence whether dominant or not, firms targeted by a PHA experience a reduction in stock market valuation at least temporarily. Table 4 (middle panel) reports pooled promotion models for the 27 therapeutic substitutes of the seven market dominant drugs. Results suggest that the manufacturers of therapeutic substitutes of market dominant agents significantly increase their promotion expenditures 3- months (49\%) and 6- months (29\%) following the PHA. This suggests manufacturers of therapeutic substitutes of market dominant drugs recognize the PHA release as an opportunity to promote their product more aggressively. Table 4 (bottom panel) reports estimated pooled changes in promotion for the dominant drugs targeted by PHAs. Results suggest that PHA targeted firms marketing drugs with dominant market shares do not change total promotion expenditures 3- months and 6- months following the PHA. Only the estimated decrease in total promotion expenditures at 6- months is statistically significant at traditional levels. Further investigation (results available upon request) suggests there is heterogeneity in this sample at the drug level in 3- and 6- month changes in promotion after PHAs. 3- months after the PHA release, we observe statistically significant decreases in total promotion spending among Adderall and Strattera, non-statistically significant decreases in promotion expenditures among Chantix, Gabitril and Duragesic, and statistically significant increases in spending for Crestor. 6- months after the PHA release, we observe statistically significant decreases in total promotion spending among Adderall, Chantix, Strattera, Gabitril and Duragesic, and statistically significant increases in spending for Crestor. 3- and 6- months following PHAs, we estimate statistically significant declines in detailing visits, 
journal ads, and free samples among Adderall, Chantix, Strattera, Gabitril and Duragesic while Crestor increased detailing and free samples.

Sensitivity analyses reveal several PHAs were mentioned in the press in the days preceding the release date (Paxil, Duragesic and Gabitril) (available upon request). However, use of these alternative dates for these drugs did not yield material differences in the estimated magnitude, direction or significance of the changes in the pooled firm valuation and promotion results. The press reported coincident but unrelated events that could affect firm valuations for three firms. These firms exhibit some limited differences in valuation changes relative to the pooled sample: Astrazeneca experienced an increase in stock price coincident with the timing of the advisory, the others (GSK and Sanofi Aventis) experienced decreases in stock price and increases in trading volumes similar in magnitude to the pooled results. An examination of the raw trends suggest no significant additional breaks in stock price, trading value or promotion preceding each PHA; the majority of drugs in the sample exhibit stable trends preceding the PHA release. One drug (Crestor) exhibits significant decreases in promotion previous to the PHA release and significant increases after the PHA; this pattern of behavior may be due to the release of studies in the medical literature preceding the PHA implicating Crestor and other class drugs with negative side effects. Other sensitivity analyses are consistent with those found in the full sample.

\section{DISCUSSION}

Following a PHA, targeted firms are observed to exhibit average 3-day stock price declines of $3 \%$ and trading volume increases of $17 \%$ and average 5 -day stock price declines of $11 \%$ and trading volumes increases of $16 \%$. On average, there are no corresponding declines in average prices or increases in trading volume for the NYSE/NASDAQ Composite Index. The magnitude of the effect of PHAs on stock valuation appears to be greater than the magnitude of the effect of Paragraph IV court decisions favoring generic firms while the direction of the two effects are the same. Three months following PHAs there are significant average decreases in journal ads (83\%) and detailing visits (29\%) to physicians, ceteris paribus. Six months following PHAs there are significant average declines in total promotion spending (46\%), journal ads (84.4\%) and detailing visits (45\%) to physicians; the number of free samples remains unchanged. Twelve months following PHAs there are no statistically significant changes in promotion. Among therapeutic substitutes, pooled 
estimation reveals no statistically significant changes in promotion three, six and twelve months following PHAs. The valuation results apply to both to market dominant and nondominant drugs targeted by a PHA, although impacts are smaller in magnitude for the dominant drugs. Furthermore, manufacturers of therapeutic substitutes of market dominant drugs appear to significantly increase promotion expenditures following PHAs, suggesting potential market stealing behavior. Results are robust to additional sensitivity checks.

To our knowledge this research is the first to examine how FDA PHAs affect market valuations of biopharmaceutical firms. The results are consistent in spirit and in direction with Panattoni (2011) who examines the effect of another type of negative information, Paragraph IV decisions, on branded firm performance. PHAs effects on firm valuations are greater in magnitude than those estimated for a matched sample of firms following Paragraph IV decisions favoring generic manufacturers. Differences in the estimated magnitudes of these two types of negative public announcements on firms are plausible given the public visibility of changes in safety profiles of FDA approved drugs and their potential impact on the remaining life-cycle of the drug; Paragraph IV decisions in Federal District Courts would be expected to be important to a smaller section of the marketplace, although critical to the firm's ability to extract super-competitive profits by the time of patent expiration.

To our knowledge this research is the first to examine firms response to the release of PHAs. Pooled estimates showing significant declines in promotion expenditures six months after PHAs are consistent in direction with work by Majumdar, Almasi, and Stafford (2004) describing substantial reductions in physician- and patient-targeted promotion expenditures on hormone replacement therapy following initial findings of the highly publicized Women's Health Initiative (WHI) report.41 Our primary insight into potential firm promotion response to the release of PHAs is that the direction and timing of changes are fundamentally dependent on the function(s) of promotion in the branded biopharmaceutical marketplace (Chart), holding regulatory rules and enforcement constant (Chart). The results documenting a decrease in promotion spending and promotion by

${ }^{41}$ See Majumdar SR, Almasi EA, Stafford RS. Promotion and prescribing of hormone replacement therapy after report of harm by the Women's Health Initiative. Journal of the American Medicine Association. 2004;292:1983-1988. 
channel are generally consistent with previous work suggesting promotion of patentprotected drugs after initial launch surge serves a predominantly persuasive role. Were the promotion predominantly informative, we would not expect reductions in promotion efforts and could see increases (Chart). Furthermore, free sample volumes do not change significantly after PHAs in all models; this result is consistent with previous work by Joseph and Mantrala (2009) suggesting promotion by this channel may serve a predominantly informational role for the patient. ${ }^{42}$ Findings segregated by market share position suggest that the degree to which promotion serves a predominantly informational versus persuasive role may differ by the availability of therapeutic substitutes and consequently the cross price elasticity of demand between potential therapeutic competitors (a finding consistent with the behavioral model). ${ }^{43}$

The FDA may consider a number of complex factors in deciding when to issue a safety alert. The valuation results suggest a potentially important consequence of FDA regulatory warnings: short-term changes in the perceived value of the firm by the marketplace. Our results suggest the agency could include the impact of the PHA on firm valuation as part of its risk-based approach. Additionally, our findings imply the FDA should generally anticipate declines in branded promotion when a PHA is released on a patent-protected drug. These declines may have indeterminate effects on consumer welfare if a portion of such promotion serves an informational role for consumers. Whether the informational or persuasive role of promotion dominates for which patent protected drugs and when over a product's lifecycle is critical to interpreting consumer welfare implications of PHAs. ${ }^{44}$

Our results are also relevant to interpreting numerous previous studies examining the impact of PHAs on the use of other therapies. ${ }^{45}$ Significant declines in promotion following

\footnotetext{
42 See Kissan J, Mantrala M. A Model of the Role of Free Drug Samples in Physicians' Prescription Decisions. Marketing Letters. 2009; 20:15-29.

${ }^{43}$ Changes in the level and intensity of product marketing between channels after a Medwatch safety advisory may also differ by drug. See Jean-Jacques Lambin 1970 and Narayanan S, Desiraju R, Chintagunta PK 2004, this is an interesting avenue for future research.

44 This suggestion is consistent with Azoulay's 2002 work on the direct and indirect effects of increasing scientific knowledge on the usage of patent-protected pharmaceuticals. 45 See for example, Alexander GC, Sehgal NL, Moloney RM, Stafford RS 2008; Dorsey ER, Rabbani A, Gallagher SA, Conti R, Alexander GC 2010; Stafford RS, Radley DC 2003; Morgan OW, Griffiths C, Majeed A. Interrupted time-series analysis of regulations to reduce
} 
a PHAs may directly and independently affect demand for a drug, ceteris paribus. The combined (and likely correlated) effect exerted on demand by the PHA and significant decreases in promotion may be larger than the sum of independent effects. Consequently, if an analyst does not take decreases in promotion into account, this omission could lead to overestimating (and misattributing) the direct effect of the PHA on drug use. Our findings suggest previous documented decreases in drug utilization in the US likely overstate the direct effect of PHAs on physician prescribing. ${ }^{46}$ The net effect of these changes on consumer welfare depends in part on the market power of the PHA targeted drug. ${ }^{47}$ The practical direction, magnitude and independent correlates of the bias should be the subject of future empirical research to inform future FDA policy-making.

The study has important limitations not discussed above. First, the study was not designed to examine other actions by firms to promote consumer welfare, which may have changed in important ways as a result of PHAs. For example, in response to a safety concern, firms could shift promotion resources to patient advocacy or other efforts to build corporate goodwill or shift away from public service activities that are complements to drug promotion. Whether and how PHAs alter corporate engagement with social messaging is an important direction for future work. Second, data availability limitations prevented an analysis of changes in promotion after PHAs targeted to specific physician specialties and/or consumers. Given the sophistication of pharmaceutical firm marketing research departments, we expect aggregate changes in promotion spending overall and by channel to

paracetamol (acetaminophen) poisoning. PLoS Med. 2007 Apr;4(4):e105; Katz LY, Kozyrskyj AL, Prior HJ, et al. Effect of regulatory warnings on antidepressant prescription rates, use of health services and outcomes among children, adolescents and young adults. CMAJ. 2008;178:1005-1011; Smalley W, Shatlin D, Wysowski DK, et al. Contraindicated use of Cisapride: impact of Food and Drug Administration Regulatory Action. Journal of the American Medicine Association. 2000;284:3036-3039; Jacoby JL, Fulton J, Cesta M, Heller M. After the black box warning: dramatic changes in ED use of droperidol. American Journal of Emergency Medicine. 2005;23:196.

${ }^{46}$ It is also possible that usage of these drugs following the advisory release may be affected by the choices of other actors, such as formulary placement by insurance coverage and reimbursement committees. Documenting the potential use of FDA Medwatch advisories for the coverage and formulary placement decisions of insurers is an important avenue for future work aiming to elucidate the components of the net effect of FDA advisories on treatment usage.

47 It is important to mention that among numerous recent examples the release of a PHA targeting one drug in a therapeutic class is subsequently followed by a class-wide PHA suggesting therapeutic substitutes may typically share potential side effect and safety profiles. 
mask important differences by physician specialty and consumer group. Finally, we examined a selected sample of PHAs targeting on-patent drugs chosen for analytical convenience. While this sample comprises a highly publicized and clinically important set of PHAs, further work is needed to describe and interpret the impact of FDA class-wide PHAs on firm valuations and potential promotion responses.

In summary, pharmaceutical firms' market valuations are negatively affected by FDA Medwatch advisory releases targeting patent-protected drugs. In response to FDA-required labeling changes, firms appear to decrease drug-specific promotion to physicians. The timing of the results suggest that while FDA advisories are likely to have an immediate impact on valuations of firms whose drugs are adversely affected, effects on promotion levels will likely occur more gradually due to the timing of regulatory review, within-firm budgeting and between-firm promotion contracts. There appears to be heterogeneity in market valuation response and promotion at the drug level, based in part on the market position of the drug with respect to potential therapeutic substitutes. While these results may be subject to some limitations, they remain important for interpreting and understanding more comprehensively provider and patient responses to recent historical FDA actions, and for informing future efforts by the FDA and drug manufacturers seeking to optimize the impact of regulatory actions on the safe and effective use of prescription medicines. 


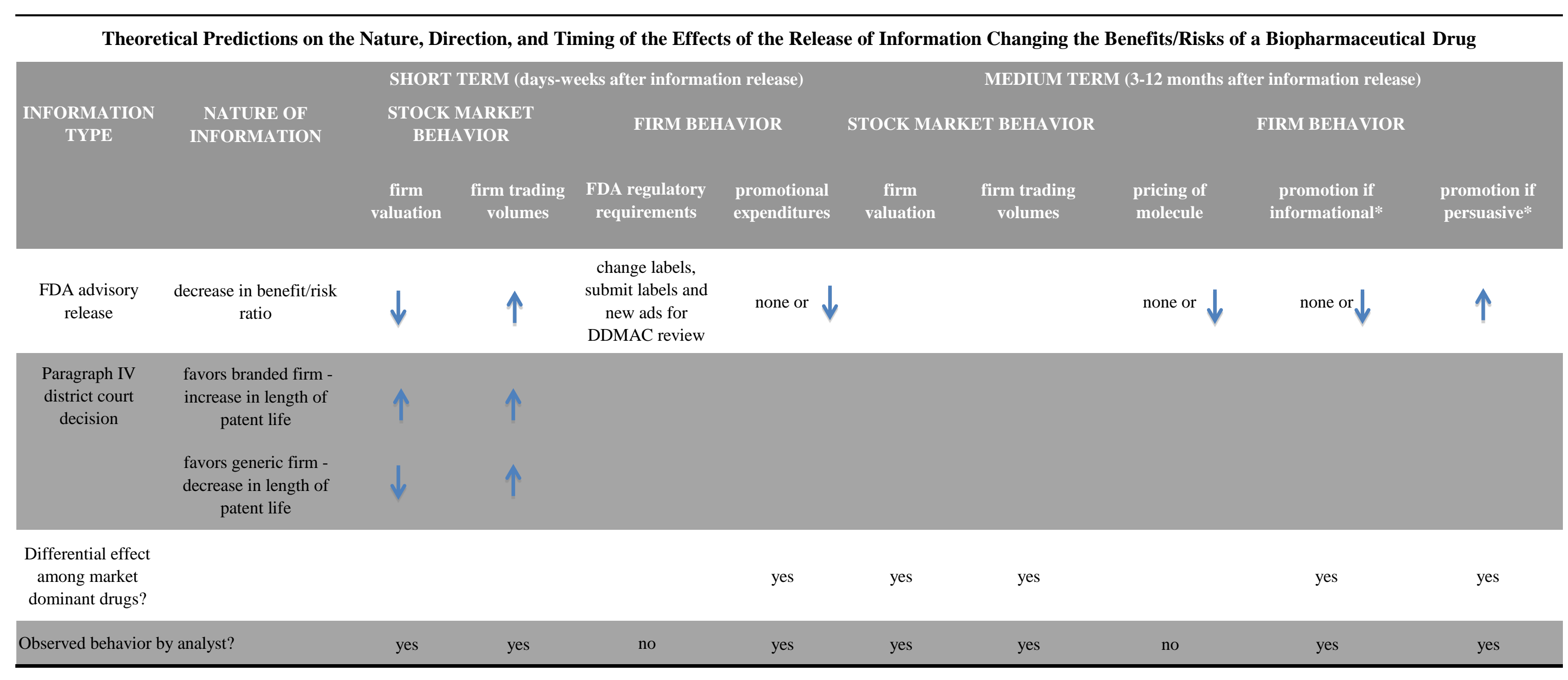




\begin{tabular}{|c|c|c|c|c|c|c|}
\hline Drug & Firm & Date of Advisory & Advisory Content & $\begin{array}{l}\text { Date of Product } \\
\text { Launch }\end{array}$ & $\begin{array}{l}\text { Estimated Market } \\
\text { Share }\end{array}$ & $\begin{array}{l}\text { Therapeutic Substitute Drug } \\
\text { Class }\end{array}$ \\
\hline Paxil $^{\mathrm{TM}}$ & GSK & $12 / 7 / 2005$ & $\begin{array}{l}\text { Pregnancy may increase the risk for congenital } \\
\text { malformations, particularly cardiac malformations }\end{array}$ & Dec. 29, 1992 & $14 \%$ & SSRIs/SNRIs \\
\hline Strattera $^{\mathrm{TM} *}$ & Lilly & $9 / 28 / 2005$ & Risk of suicidal thinking in children and adolescents & Nov. 26,2002 & $18 \%$ & psychostimulants \\
\hline Duragesic $^{\mathrm{TM} *}$ & Janssen & 7/14/2005 & Deaths and overdoses & Aug. 7, 1990 & $2 \%$ & $\begin{array}{c}\text { opoid based pain medications/ } \\
\text { narcotic analgesics }\end{array}$ \\
\hline Crestor ${ }^{\mathrm{TM} *}$ & Astrazeneca & $3 / 1 / 2005$ & $\begin{array}{l}\text { Advanced age ( }>65 \text { years), have hypothyroidism, } \\
\text { and/or renal insufficiency should be considered to } \\
\text { have a greater risk for developing myopathy }\end{array}$ & Aug. 12, 2003 & $9 \%$ & statins \\
\hline Elidel $^{\mathrm{TM}}$ & Novartis & 3/9/2005 & Linked to cancer & Dec. 13, 2001 & $18 \%$ & topical steroids \\
\hline Gabitril $^{\mathrm{TM} *}$ & Cephalon & 2/17/2005 & Risk of seizures in patients without epilepsy & Sep. 30, 1997 & $36 \%$ & benzodiazepines \\
\hline Adderall $^{\mathrm{TM} *}$ & Shire & 2/8/2005 & $\begin{array}{l}\text { Canadian drug regulatory agency has suspended the } \\
\text { sale of Adderall XR in the Canadian market }\end{array}$ & Oct. 11, 2001 & $49 \%$ & psychostimulants \\
\hline Ketek $^{\mathrm{TM}}$ & Aventis & $1 / 19 / 2006$ & Increased frequency of liver-related adverse events & 31-Mar-00 & $11 \%$ & macrolide based antibiotics \\
\hline Chantix ${ }^{\mathrm{TM} *}$ & Pfizer & $1 / 31 / 2008$ & Severe changes in mood and behavior & 9-May-02 & $55 \%$ & $\begin{array}{l}\text { Zyban }^{\mathrm{TM}} / \text { Wellbutrin } \\
\text { (bupropion) listed as } \\
\text { "antismoking uses" }\end{array}$ \\
\hline \multicolumn{7}{|c|}{$\begin{array}{l}\text { * indicates first in class or high market share molecules (usage }>20 \% \text { of ATC class in month previous to advisory) } \\
\text { Market share is calculated as the usage of the molecule in the month previous to the advisory release as a percentage of total usage of therapeutic class substitutes based on ATC system. Data } \\
\text { from IMS Health's National Disease and Therapeutic Index }{ }^{\mathrm{TM}} \text { was used to calculate market share. } \\
\text { Date of advisory and summary of the advisory content is taken from the FDA website. } \\
\text { Date of product launch is taken from the FDA Orange book. } \\
\text { Therapeutic class substitutes are derived from the ATC system. }\end{array}$} \\
\hline
\end{tabular}




\begin{tabular}{|c|c|c|c|c|}
\hline \multicolumn{5}{|c|}{$\begin{array}{c}\text { TABLE 2. OLS Estimated Changes in Stock Valuation and T } \\
\text { Advisories }\end{array}$} \\
\hline & \multicolumn{2}{|c|}{ price } & \multicolumn{2}{|c|}{ volume } \\
\hline & 3 days & 5 days & 3 days & 5 days \\
\hline \multicolumn{5}{|c|}{ In sample firms targeted by FDA advisories } \\
\hline percent effect & -3.120 & -11.000 & 17.100 & 16.200 \\
\hline percent variation & 0.400 & 0.600 & 17.200 & 36.200 \\
\hline $\mathbf{z}$ & -7.800 & -18.333 & 0.994 & 0.448 \\
\hline \multicolumn{5}{|c|}{ Comparison group 1: NASDAQ composite index } \\
\hline percent effect & 4.350 & 6.710 & 11.300 & 14.000 \\
\hline percent variation & 3.560 & 4.100 & 23.400 & 18.300 \\
\hline $\mathbf{z}$ & 1.222 & 1.637 & 0.483 & 0.765 \\
\hline \multirow{2}{*}{\multicolumn{5}{|c|}{$\begin{array}{c}\text { Comparison group 2: Firms with Paragraph IV District Court Decisions matched to in-sample firms targeted by FDA } \\
\text { advisories } \\
\text { decision favors branded drug }\end{array}$}} \\
\hline & & & & \\
\hline percent effect & 2.100 & 2.600 & 23.400 & 34.100 \\
\hline percent variation & 1.000 & 1.000 & 12.200 & 11.300 \\
\hline $\mathbf{z}$ & 2.100 & 2.600 & 1.918 & 3.018 \\
\hline \multicolumn{5}{|c|}{ decision favors generic drug } \\
\hline percent effect & -1.200 & -1.100 & 6.780 & 5.300 \\
\hline percent variation & 0.210 & 0.360 & 6.000 & 7.800 \\
\hline $\mathbf{z}$ & -5.714 & -3.056 & 1.130 & 0.679 \\
\hline $\begin{array}{l}\text { Bold indicates statis } \\
\text { Log dependent varic } \\
\text { Reported percent ef } \\
\text { Data are derived fro }\end{array}$ & $\begin{array}{l}\text { the } 2.0 \\
\text { mated a } \\
\text { ariation } \\
\text { ASDAQ }\end{array}$ & $\begin{array}{l}\text { olute valu } \\
\text { asonality } \\
\text { coeffici } \\
\text { ork Stock }\end{array}$ & $\begin{array}{l}\text { (coefficie } \\
\text { listed in }\end{array}$ & ck Market Index ${ }^{\mathrm{TM}}$ \\
\hline
\end{tabular}




\begin{tabular}{|c|c|c|c|c|c|c|c|c|c|c|c|c|}
\hline & \multicolumn{3}{|c|}{ total promotion expenditures } & \multicolumn{3}{|c|}{ count of journal ads } & \multicolumn{3}{|c|}{ number of samples } & \multicolumn{3}{|c|}{ number of detailing visits } \\
\hline & 3 months & 6 months & 12 months & 3 months & 6 months & 12 months & 3 months & 6 months & 12 months & 3 months & 6 months & 12 months \\
\hline \multicolumn{13}{|c|}{ Affected Sample Branded Drugs } \\
\hline percent effect & -26.655 & -46.206 & -34.949 & -82.967 & -84.118 & -87.381 & -17.304 & -41.725 & -27.385 & -28.823 & -45.119 & -41.725 \\
\hline percent variation & 18.530 & 22.140 & 33.643 & 41.907 & 22.140 & 171.828 & 27.762 & 48.736 & 48.290 & 13.883 & 22.262 & 22.140 \\
\hline $\mathbf{z}$ & -1.438 & -2.087 & -1.039 & -1.980 & -3.799 & -0.509 & -0.623 & -0.856 & -0.567 & -2.076 & -2.027 & -1.885 \\
\hline \multicolumn{13}{|c|}{38 Branded Therapeutic Substitute Drugs, Unaffected by Advisory } \\
\hline percent effect & 0.200 & -12.190 & -24.422 & -1.980 & 2.020 & -4.877 & 1.005 & -14.786 & -30.927 & -7.688 & -13.929 & -26.655 \\
\hline percent variation & 17.586 & 18.530 & 20.925 & 6.396 & 11.182 & 4.081 & 26.871 & 56.831 & 17.468 & 10.738 & 12.750 & 40.495 \\
\hline $\mathbf{z}$ & 0.011 & -0.658 & -1.167 & -0.310 & 0.181 & -1.195 & 0.037 & -0.260 & -1.770 & -0.716 & -1.093 & -0.658 \\
\hline $\begin{array}{l}\text { Promotion data are } \\
\text { Bold indicates stati } \\
\text { Log dependent vari } \\
\text { Reported percent ef }\end{array}$ & $\begin{array}{l}\text { en from Int } \\
\text { ally signific } \\
\text { e models ar } \\
\text { ts and perc }\end{array}$ & $\begin{array}{l}\text { grated Pror } \\
\text { int at the } 2 . \\
\text { estimated } \\
\text { tt variation }\end{array}$ & $\begin{array}{l}\text { tional Servic } \\
\text { or greater ab } \\
\text { justing for se } \\
\text { re transforme }\end{array}$ & $\begin{array}{l}\operatorname{ces}^{\mathrm{TM}} \text {. } \\
\text { solute val } \\
\text { easonality } \\
\text { ed coeffici }\end{array}$ & $\begin{array}{l}\text { vel. } \\
\text { first orc } \\
100(\mathrm{ex}]\end{array}$ & $\begin{array}{l}\text { utocorre } \\
\text { efficient }\end{array}$ & (AR1). & & & & & \\
\hline
\end{tabular}


Table 4. Estimated Changes in Stock Valuations and Trading Volumes After FDA Advisory Releases Among Firms and Estimated Changes in Promotional Expenditures for the 6 Market Dominant Drugs

\section{OLS Estimated Changes in Stock Valuation and Trading Volumes Among Affected Firms}

price

volume

\begin{tabular}{|c|c|c|c|c|}
\hline percent effect & -2.400 & -3.100 & 14.400 & 18.200 \\
\hline percent variation & 1.100 & 1.400 & 4.700 & 14.200 \\
\hline $\mathbf{z}$ & -2.182 & -2.214 & 3.064 & 1.282 \\
\hline GEE Estimated & in Promot & $\begin{array}{l}\text { tures Amo } \\
\text { Drugs }\end{array}$ & utic Subst & ret Don \\
\hline & & omotion es & & \\
\hline & 3 months & 6 months & 12 months & \\
\hline percent effect & 49.332 & 29.175 & 13.655 & \\
\hline percent variation & 24.234 & 12.975 & 12.075 & \\
\hline $\mathbf{z}$ & 2.036 & 2.249 & 1.131 & \\
\hline GEE & d Change & al Expent & 6 Market & \\
\hline & & omotion e: & & \\
\hline & 3 months & 6 months & 12 months & \\
\hline percent effect & -4.877 & 0.290 & 0.450 & \\
\hline percent variation & 5.338 & 63.232 & 49.182 & \\
\hline $\mathbf{z}$ & -0.914 & 0.005 & 0.009 & \\
\hline $\begin{array}{l}\text { Data are derived fro } \\
\text { CRSP Daily Stock } \\
\text { Promotion data are } \\
\text { Bold indicates statis } \\
\text { Reported percent ef }\end{array}$ & $\begin{array}{l}\text { aposite NA } \\
\text { dex } \\
\text { IMS Hea } \\
\text { nificant at } \\
\text { percent var }\end{array}$ & $\begin{array}{l}\text { New York } \\
\text { Promotion } \\
\text { ter absolut } \\
\text { formed co }\end{array}$ & $\begin{array}{l}\mathrm{e}^{\mathrm{TM}} \text { listed in } \\
\mathrm{xp} \text { (coefficie }\end{array}$ & \\
\hline
\end{tabular}




\begin{tabular}{|c|c|c|c|c|}
\hline \multicolumn{5}{|c|}{$\begin{array}{c}\text { APPENDIX. Paragraph IV District Court Decisions Included In Analysis For Comparative } \\
\text { Purposes }\end{array}$} \\
\hline brand & company & decision & announcement & winner \\
\hline Augmentin ${ }^{\mathrm{TM}}$ & GSK & $7 / 19 / 2002$ & $5 / 23 / 2002$ & generic \\
\hline Relafen $^{\mathrm{TM}}$ & GSK & $8 / 14 / 2001$ & $8 / 14 / 2001$ & generic \\
\hline Zofran ${ }^{\mathrm{TM}}$ & GSK & $8 / 20 / 2004$ & $8 / 24 / 2004$ & brand \\
\hline Prozac $^{\mathrm{TM}}$ & Lilly & $1 / 12 / 1999$ & 1/13/1999 & brand \\
\hline Zyprexa $^{\mathrm{TM}}$ & Lilly & $4 / 14 / 2005$ & $4 / 14 / 2005$ & brand \\
\hline Sporonox ${ }^{\mathrm{TM}}$ & Janssen & $7 / 28 / 2004$ & $7 / 29 / 2004$ & generic \\
\hline Prilosec ${ }^{\mathrm{TM}}$ & Astrazeneca & $10 / 11 / 2002$ & $10 / 11 / 2002$ & brand \\
\hline Toprol xl ${ }^{\mathrm{TM}}$ & Astrazeneca & $1 / 17 / 2006$ & $1 / 18 / 2006$ & generic \\
\hline Accupril & Pfizer & $6 / 28 / 2004$ & $6 / 30 / 2004$ & brand \\
\hline Celebrex ${ }^{\mathrm{TM}}$ & Pfizer & $3 / 20 / 2007$ & $3 / 20 / 2007$ & brand \\
\hline Lipitor $^{\mathrm{TM}}$ & Pfizer & $12 / 16 / 2005$ & $12 / 16 / 2005$ & brand \\
\hline \multicolumn{5}{|c|}{$\begin{array}{l}\text { Sample universe and district court decisions taken from Panattoni LE, The effect of Paragraph IV decisions and } \\
\text { generic entry before patent expiration on brand pharmaceutical firms, Journal of Health Economics, Volume 30, } \\
\text { Issue 1, January 2011, Pages 126-145. }\end{array}$} \\
\hline
\end{tabular}

